\title{
A Study of Relationship Between Maternal Vitamin D Status and Mode of Delivery in a Tertiary Care Military Hospital
}

\section{Gurpreet Kaur Dhillon}

Armed forces medical services

\section{Suneeta Singh}

Armed forces medical services

\section{Harpreet Singh Dhillon}

Armed forces medical services https://orcid.org/0000-0001-5956-874X

Shibu Sasidharan ( $\nabla$ shibusasi@gmail.com )

Armed forces medical services

\section{Research}

Keywords: Vitamin D deficiency, LSCS, Newborn, Cord blood vitamin D

Posted Date: June 18th, 2020

DOl: https://doi.org/10.21203/rs.3.rs-35417/v1

License: (c) (1) This work is licensed under a Creative Commons Attribution 4.0 International License. Read Full License 


\section{Abstract}

Background: Vitamin D deficiency has been shown to be related to multiple adverse pregnancy related outcomes. An observational study was undertaken to study the relationship between maternal serum vitamin $\mathrm{D}$ levels during peripartum period and outcome in the form of mode of delivery.

Methods: This study was done in a tertiary care centre on 569 patients to study the relationship between maternal serum vitamin D levels and mode of delivery categorized into vaginal delivery (VD), (including assisted delivery) and Lower Segment Cesarean Section (LSCS). The primary objective of this project was to assess the vitamin D levels in maternal serum and to study its relationship, if any, with mode of delivery.

Results: A total of 569 samples of maternal and neonatal serum were analyzed for serum 25(OH)D levels. 464 (81.54\%) mothers had Vitamin D sufficient (VDS) levels $\geq 30 \mathrm{ng} / \mathrm{ml}$ and 105 (18.45\%) had vitamin D deficient (VDD) levels $<30 \mathrm{ng} / \mathrm{ml}$. Out of total 569 newborns; LSCS and spontaneous Vaginal Delivery were $152(26.71 \%)$ and $417(73.28 \%)$ respectively. The incidence of LSCS was $19.61 \%$ in the vitamin D sufficient group as compared to $58.09 \%$ in the vitamin D deficient group $(p<0.0005)$. The mean cord blood $25(\mathrm{OH}) \mathrm{D}$ levels of the neonates born by vaginal delivery was $14.05 \mathrm{ng} / \mathrm{ml}$ (SD 3.86, range 8.2-27) whereas those born by LSCS was $12.11 \mathrm{ng} / \mathrm{ml}$ (SD 3.18, range 7.9-22), which was significantly lower $(\mathrm{p}<0.00000042)$.

Conclusion: The rates of Cesarean section deliveries was 2.96 times higher in mothers who had deficient Vitamin D levels. Also the levels of mean cord blood vitamin D was higher in vaginally delivered newborns.

\section{Introduction}

Vitamin D deficiency is a major global public health issue with around 1 billion people worldwide having vitamin D deficiency ${ }^{[1]}$. Various studies have described hypovitaminosis $\mathrm{D}$ and osteomalacia among south Asian women especially during pregnancy ${ }^{[2,3]}$. Vitamin D deficiency is prevalent in Indian women despite being a tropical country with abundant sunshine, which could be attributed to prevalent strict social and cultural practices that prohibit adequate sunshine exposure of adolescent girls, young women and newly married females ${ }^{[4]}$. In a population with high prevalence of vitamin D deficiency and poor dietary calcium intake, the problem is likely to compound during pregnancy due to increased demand by the growing fetus ${ }^{[5,6,7]}$. Recent studies have reported a link between maternal vitamin $D$ deficiency and adverse pregnancy outcomes such as pre-eclampsia ${ }^{[8]}$, gestational diabetes ${ }^{[9]}$, small-for-gestational-age ${ }^{[10]}$, caesarean section ${ }^{[11]}$ and bacterial vaginosis ${ }^{[12]}$. The mode of delivery depends on a multitude of factors. One of the important factors that favour normal vaginal delivery is the structure of the maternal birth passage and the muscular efforts involved in the process of expulsion of the fetus from the uterus. Severe vitamin D deficiency and rickets in women can cause pelvic deformities, which poses increased risk of obstructed labor leading to assisted/instrumental delivery ${ }^{[11]}$. Reduction in strength of pelvic 
musculature is hypothesized to be another possible reason for the potential higher risk of cesarean delivery in women with lower vitamin D concentrations ${ }^{[13]}$. In addition to playing a vital role in calcium homeostasis and bone mineralization, vitamin $\mathrm{D}$ concentration is critical for muscle performance also. The active metabolite of vitamin D, 1,25-dihydroxyvitamin D, binds to a vitamin D-specific nuclear receptor ${ }^{[14]}$ in muscle tissue which leads to de novo protein synthesis, muscle cell growth ${ }^{[15]}$ and improved muscle function ${ }^{[16]}$. Studies in isolated myometrial cells have reported that by altering the concentration of extracellular calcium or inhibiting the entry of the ion into the cell, the contractility of muscle fibres can be altered $^{[17,18]}$. The use of tocolytics (calcium channel inhibitors) to prevent preterm delivery is based on this observation ${ }^{[19]}$.

The available research on the role of maternal vitamin $D$ status and mode of delivery is at best ambivalent due to methodological variability and multitude of reasons dictating the modes of delivery. Merewood et.al. ${ }^{[11]}$ (2009) in a study of 300 mothers reported a four-fold rise in incidence of cesarean delivery when maternal Vitamin D levels were less than $37.5 \mathrm{nmol} / \mathrm{L}$ compared to mothers with higher Vitamin D levels. Scholl ${ }^{[20]}$ analysed a cohort of 1153 low-income minority pregnant women and reported a significantly higher risk of caesarean section in women with vitamin D concentrations lower than $30 \mathrm{nmol} / \mathrm{L}$. Sakineh et al ${ }^{[21]}$ (2015) in a triple blind randomized controlled trial studied 126 pregnant ladies to determine the effect of maternal Vitamin D levels with mode of delivery. Subjects were divided into 03 groups and received vitamin $D$, calcium plus vitamin $D$ and placebo pills daily for 60 days. This study reported that rates of cesarean section were similar for the three groups, $66.7 \%$ in the calcium + Vitamin D group; $71.4 \%$ in the only Vitamin D group and $61.9 \%$ in the placebo group. In a British study after excluding cofactors such as BMl, ethnicity and age, no differences were observed in vitamin $D$ concentrations between women who delivered vaginally or had elective/emergency caesarean section [22]. A meta-analysis ${ }^{[23]}$ of randomized controlled trials to evaluate the effect of vitamin D supplementation on the risk of caesarean section found no effect. Fernández-Alonso $\mathrm{AM}^{[24]}$ et al (2012) and Zhou J et al ${ }^{[25]}$ (2014) in separate studies on Spanish and Chinese women found no association between the first trimester vitamin $\mathrm{D}$ concentration and the risk of caesarean section. Thus, there is at present insufficient evidence about the association of vitamin $D$ deficiency during pregnancy and the risk of caesarean section among the armed forces and their dependants. The relative lack of literature on this subject especially in Indian scenario is sought to be addressed by this study.

\section{Materials And Methods}

\section{Study design:}

Observational Study

\section{Sample population:}


The Institutional Ethics Committee approved the study protocol and informed consent was obtained from the study subjects. The study subjects were healthy pregnant women and their newborns. The Military hospital caters for families from all parts of the country with all subjects belonging to the upper middle socioeconomic status (Kuppuswamy scale) and residing in urban area. All the women were literate and none of them suffered from malnutrition or indulged in cultural practices like purdah, hijab, etc. which would have affected the synthesis of Vitamin D. All the study subjects had unrestricted access to free tertiary medical care.

\section{Inclusion criteria:}

1. Healthy pregnant women without any co-morbidities and their newborn.

\section{Exclusion criteria:}

1. Pregnancy losses, spontaneous abortion and still birth are excluded.

2. Twin/triplet were excluded because of their high risk of PTB, LBW, LSCS [26].

3. Known history or evidence of Rheumatoid arthritis, Thyroid, Parathyroid, Adrenal diseases, Hepatic or Renal failure.

4. Metabolic bone disease

5. Type 1 diabetes and malabsorption diseases

\section{Methodology}

A total of 569 pregnant ladies were recruited into the study group after applying inclusion and exclusion criterion. The data for this observational study included maternal and neonatal (cord blood) blood samples taken during peri-partum period and mode of delivery categorized into Vaginal delivery (VD), (including assisted delivery) and Lower Segment Cesarean Section (LSCS). The primary objective of this project was to assess the vitamin D status in maternal serum and to study its relationship, if any, with mode of delivery. A comparison between neonatal vitamin D levels taken from cord blood and mode of delivery was also studied. Analysis of the data was done using SPSS software (Version 20). Statistical analysis was done using Students-t test. A ' $p$ ' value of $<0.05$ was taken as statistically significant. The 25(OH)D levels more tah $30 \mathrm{ng} / \mathrm{ml}$ were taken a sufficient and less than $30 \mathrm{ng} / \mathrm{ml}$ was taken as deficient as per US Endocrine Society Classification ${ }^{[27]}$.

\section{Observations And Results}

A total of 569 samples were collected for the study from the maternal serum during peripartum period. There were 252(44.2\%) males and 317(55.7\%) female newborns. 


\section{a) Maternal serum vitamin D levels-}

Maternal vitamin D levels are described in table no. 1. The mean serum 25(OH) D level of the mothers was $35.63 \mathrm{ng} / \mathrm{ml}$ (SD 6.18, range 9.2-49). Out of the total 569 mothers enrolled in this study, 464 (81.54\%) had sufficient Vitamin D (VDS) levels ( $\geq 30 \mathrm{ng} / \mathrm{ml})$ and $105(18.45 \%)$ had vitamin D deficient (VDD) levels (<30ng/ml).

Table 1: Maternal vitamin D levels.

\begin{tabular}{|ll|}
\hline & Maternal 25(OH) levels \\
\hline $\mathrm{n}$ & 569 \\
\hline Mean $(\mathrm{ng} / \mathrm{ml})$ & 35.63 \\
\hline $\mathrm{SD}$ & 6.18 \\
\hline Range $(\mathrm{ng} / \mathrm{ml})$ & $9.2-39.8$ \\
VDS $(\%)$ & $464(81.54 \%)$ \\
\hline VDD $(\%)$ & $105(18.45 \%)$ \\
\hline *VDS=Vitamin D sufficient, VDD=Vitamin D deficiency. \\
\hline
\end{tabular}

\section{b) Mode of delivery of newborns-}

Table 2 illustrates the distribution of newborns with respect to mode of delivery in which by LSCS and spontaneous Vaginal Delivery were $152(26.71 \%)$ and 417 (73.28\%) respectively.

Table 2 - Distribution of newborns with respect to mode of

\begin{tabular}{|lll|}
\multicolumn{3}{c}{ delivery } \\
\hline - & NUMBERS & PERCENTAGE \\
\hline VD & 417 & $73.28 \%$ \\
\hline LSCS & 152 & $26.71 \%$ \\
\hline TOTAL & 569 & $100 \%$ \\
\hline * VD- vaginal delivery, LSCS- lower segment caesarean section \\
\hline
\end{tabular}

\section{c) Rate of LSCS and maternal vitamin D}

Table 3 illustrates the incidence of mode of delivery in vitamin D sufficient (VDS) and Vitamin D deficient (VDD) mothers. The incidence of LSCS was $19.61 \%$ in the sufficient group as compared to $58.09 \%$ in the 
vitamin $D$ deficient group. On comparison of the two values using students ' $t$ ' test the $p$ value was found to be $(<0.0005)$, which was highly significant.

Table 3: Rate of LSCS and vaginal delivery in VDS and VDD mothers

\begin{tabular}{|llll}
\hline- & $\mathrm{n}$ & LSCS & VD \\
\hline VDS & 464 & $\mathbf{9 1 ( 1 9 . 6 1 \% )}$ & $373(80.38 \%)$ \\
\hline VDD & 105 & $\mathbf{6 1 ( 5 8 . 0 9 \% )}$ & $44(41.90 \%)$ \\
\hline Total & 569 & $152(26.71 \%)$ & $417(73.28 \%)$ \\
$\begin{array}{l}\text { *VD- vaginal delivery, } \\
\text { D deficiency }\end{array}$ & & & \\
\hline
\end{tabular}

d) Neonatal vitamin D levels and mode of delivery: खOf the 569 neonates, $417(73.28 \%)$ were born by Spontaneous vaginal delivery and $\mathbf{1 5 2}(26.71 \%)$ were born by Cesarean Section. The mean cord blood $25(\mathrm{OH}) \mathrm{D}$ level of the neonates born by vaginal delivery was $14.05 \mathrm{ng} / \mathrm{ml}$ (SD 3.86, range 8.2-27) whereas those born by LSCS was 12.11(SD 3.18, range 7.9-22), which was significantly lower ( $\mathbf{p}$ value $<0.00000042)$. All the newborns were deficient in serum vitamin $D$ levels $(<30 \mathrm{ng} / \mathrm{ml})$.

Table 4: Cord Blood Vitamin D levels in neonates born by various modes of delivery.

\begin{tabular}{|lll|}
\hline & Vaginal Delivery (VD) & LSCS \\
\hline $\mathrm{n}$ & 417 & \\
\hline Mean $(\mathrm{ng} / \mathrm{ml})$ & 14.05 & 152 \\
\hline $\mathrm{SD}$ & 3.86 & 3.11 \\
\hline Range $(\mathrm{ng} / \mathrm{ml})$ & $8.2-27$ & $7.9-22$ \\
\hline
\end{tabular}

\section{Discussion}

This study attempted to evaluate the relationship between the maternal vitamin D levels and its outcome in the form mode of delivery. Out of the total 569 cases, 417 (73.28\%) delivered vaginally and $152(26.71 \%)$ underwent LSCS. In the maternal vitamin D distribution, $464(81.54 \%)$ had sufficient vitamin D (VDS) levels ( $\geq 30 \mathrm{ng} / \mathrm{ml}$ ) and $105(18.45 \%)$ had vitamin D deficient (VDD) levels ( $<30 \mathrm{ng} / \mathrm{ml})$. Out of 105 vitamin D deficient mothers, 61(58.09\%) underwent LSCS in comparison to $91(19.61 \%)$ of the vitamin D sufficient mothers and this difference was highly significant $(p<0.00001)$. The rate of Cesarean Deliveries was 2.96 times higher in mothers who had deficient Vitamin D levels $(<30 \mathrm{ng} / \mathrm{ml})$. Merewood $A^{[11]}$ (2009) obtained similar results with fourfold increase in rates of caesarean section in 
women with vitamin $D$ levels below $37.5 \mathrm{nmol} /$ liter $(P=0.012)$ after controlling for race, age, education level, insurance status and alcohol use. Another result similar to our study was reported by Scholl [20] during his analysis of a cohort of 1153 low-income minority pregnant women in which vitamin $D$ deficiency was linked to a 2-fold increased risk of cesarean. Loy SL et al ${ }^{[28]}$ (2015) studied 1152 multiethnic Asian pregnant women, out of which, 388 (41.3\%) women had vitamin D inadequacy. Of these, 131 (33.8\%), 155 (39.9\%) and 102 (26.3\%) were Chinese, Malay and Indian respectively. After adjusting the confounding variables, a trend between $250 \mathrm{HD}$ inadequacy and higher likelihood of emergency caesarean section (Odds Ratio $(O R)=1.39,95 \% \mathrm{Cl}=0.95,2.05$ ) was observed. However, Sakineh et al [21] (2015) in a triple blind randomized controlled trial on 126 pregnant ladies, found no relation between vitamin $\mathrm{D}$ and mode of delivery. This result is not consistent with the results of present study. The possible explanation for this finding is that over one third $(34.1 \%)$ of caesarian deliveries in the study by Sakineh et al were due to previous caesarian surgery or elective caesarian delivery. In a meta-analysis by Pérez-López, Faustino R. ${ }^{24]}$ et al (2015), 4 RCTs were pooled but no significant effect was found for vitamin $D$ supplementation on cesarean section rates. The possible explanation could be that indications for a caesarean section are quite variable, relating to the obstetric experience, hospital facilities etc.

The strength of this study is that a relatively uniform sample in terms of socioeconomic status, urban and literate population with unrestricted access to free tertiary medical care was studied. Secondly sampling for vitamin $D$ was done during the peripartum period when levels of vitamin $D$ are not falsely high as compared to first and second trimester ${ }^{[29]}$. The limitations were that out of the multitude reasons dictating modes of delivery, the findings of present study can not be simply generalised.

\section{Conclusion}

The rates of Cesarean section deliveries was 2.96 times higher in mothers who had deficient Vitamin $D$ levels as compared to mothers who had sufficient Vitamin D levels. The levels of mean cord blood vitamin $\mathrm{D}$ was also higher in vaginally delivered newborns. However, due to conflicting results from related studies, further research is warranted.

\section{Declarations}

\section{CONFLICTS OF INTEREST}

All authors have none to declare.

\section{ETHICAL APPROVAL AND CONSENT TO PARTICIPATE}

The Institutional Ethics Committee approved the study protocol and informed consent was obtained from the study subjects. 


\section{CONSENT FOR PUBLICATION}

Taken

\section{AVAILABILITY OF DATA AND MATERIALS}

The data sets analysed during the current study are available from the corresponding author on reasonable request.

\section{COMPETING INTERESTS}

The authors declare that they have no competing interests

\section{FUNDING}

Nil

\section{AUTHORS' CONTRIBUTIONS}

All authors have contributed partly or wholly in all or at least 3 of - Study conception and design, Acquisition of data, Analysis and interpretation of data, Drafting of manuscript, Critical revision.

\section{ACKNOWLEDGEMENTS}

The authors would like to thank all the subjects who consented to participate in this study.

\section{References}

1. Nair R, Maseeh A. Vitamin D: The "sunshine" vitamin. Journal of pharmacology \& pharmacotherapeutics. 2012 Apr;3(2):118.

2. Goswami R, Gupta N, Goswami D, Marwaha RK, Tandon N, Kochupillai N. Prevalence and significance of low 25-hydroxyvitamin D concentrations in healthy subjects in Delhi. The American journal of clinical nutrition. 2000 Aug 1;72(2):472-5.

3. Heckmatt J, Davies AJ, Peacock M, Mcmurray J, Isherwood D. Plasma 25-hydroxyvitamin D in pregnant Asian women and their babies. The Lancet. 1979 Sep 15;314(8142):546-9.

4. Sachan A, Gupta R, Das V, Agarwal A, Awasthi PK, Bhatia V. High prevalence of vitamin D deficiency among pregnant women and their newborns in northern India. The American journal of clinical nutrition. 2005 May 1;81(5):1060-4. 
5. Doi M, Rekha RS, Ahmed S, Okada M, Roy AK, El Arifeen S, Ekström EC, Raqib R, Wagatsuma Y. Association between calcium in cord blood and newborn size in Bangladesh. British Journal of Nutrition. 2011 Nov 14;106(09):1398-407.

6. Bowyer L, Catling-Paull C, Diamond T, Homer C, Davis G, Craig ME. Vitamin D, PTH and calcium levels in pregnant women and their neonates. Clinical endocrinology. 2009 Mar 1;70(3):372-7.区

7. Mawer EB, Lumb GA, Schaefer K, Stanbury SW. The metabolism of isotopically labelled vitamin D3 in man: the influence of the state of vitamin D nutrition. Clinical science. 1971 Jan 1;40(1):39-53.『

8. Bodnar LM, Catov JM, Simhan HN, et al. (2007) Maternal vitamin D deficiency increases the risk of preeclampsia. J Clin Endocrinol Metab 92, 3517-3522.

9. Zhang C, Qiu C, Hu FB, et al. (2008) Maternal plasma 25-hydroxyvitamin D concentrations and the risk for gestational diabetes mellitus. PLoS One 3, e3753.

10. Bodnar LM, Catov JM, Zmuda JM, et al. (2010) Maternal serum 25-hydroxyvitamin D concentrations are associated with small-for-gestational age births in white women. J Nutr 140, 999 - 1006.

11. Merewood A, Mehta SD, Chen TC, et al. (2009) Association between vitamin D deficiency and primary cesarean section. J Clin Endocrinol Metab 94, 940-945.

12. Dawodu, A.; Akinbi, H. Vitamin D nutrition in pregnancy: Current opinion. Int. J. Womens Health 2013, 5, 333-343. घ

13. Dovnik A, Mujezinović $F$. The association of vitamin D levels with common pregnancy complications. Nutrients. 2018 Jul;10(7):867.

14. Simpson RU, Thomas GA \& Arnold AJ (1985) Identification of 1,25-dihydroxyvitamin D3 receptors and activities in muscle. J Biol Chem 260, 8882-8891.

15. Boland R (1986) Role of vitamin D in skeletal muscle function. Endocr Rev 7, $434-447$.

16. Bischoff-Ferrari HA, Dietrich T, Orav EJ, et al. (2004) Higher 25-hydroxyvitamin D concentrations are associated with better lower extremity function in both active and inactive persons aged $\$ 60 \mathrm{y}$. Am J Clin Nutr 80, 752 - 728.

17. Fu X, Liu YJ, Ciray N, et al. (2000) Oxytocin-induced oscillations of cytoplasmic ca ${ }^{2+}$ in human myometrial cells. Acta Obstet Gynecol Scand 79, $174-179$.

18. Perusquia M \& Kubli-Garfias C (1992) External calcium dependence of the uterine contraction induced by prostaglandins E2 and F2 alpha and its antagonism with natural progestins. Prostaglandins 43, 445-455.

19. Koks CA, Brolmann HA, de Kleine MJ, et al. (1998) A randomized comparison of nifedipine and ritodrine for suppression of preterm labor. Eur J Obstet Gynecol Reprod Biol 77, 171-176.

20. Scholl TO, Chen X, Stein P. Maternal vitamin D status and delivery by cesarean. Nutrients. 2012 Apr;4(4):319-30.

21. Mohammad-Alizadeh-Charandabi S, Mirghafourvand M, Mansouri A, Najafi M, Khodabande F. The effect of vitamin $D$ and calcium plus vitamin $D$ during pregnancy on pregnancy and birth outcomes: a randomized controlled trial. Journal of caring sciences. 2015 Mar;4(1):35. 
22. Savvidou MD, Makgoba M, Castro PT, Akolekar R, Nicolaides KH. First-trimester maternal serum vitamin D and mode of delivery. British journal of nutrition. 2012 Dec;108(11):1972-5.

23. Pérez-López FR, Pasupuleti V, Mezones-Holguin E, Benites-Zapata VA, Thota P, Deshpande A, Hernandez AV. Effect of vitamin D supplementation during pregnancy on maternal and neonatal outcomes: a systematic review and meta-analysis of randomized controlled trials. Fertility and sterility. 2015 May 1;103(5):1278-88.

24. Fernández-Alonso AM, Dionis-Sánchez EC, Chedraui P, González-Salmerón MD, Pérez-López FR, Spanish Vitamin D and Women's Health Research Group. First-trimester maternal serum 25hydroxyvitamin D3 status and pregnancy outcome. International Journal of Gynecology \& Obstetrics. 2012 Jan;116(1):6-9.

25. Zhou J, Su L, Liu M, Liu Y, Cao X, Wang Z, Xiao H. Associations between 25-hydroxyvitamin D levels and pregnancy outcomes: a prospective observational study in southern China. European journal of clinical nutrition. 2014 Aug;68(8):925-30.

26. Clausson B, Cnattingius S, Axelsson O. Preterm and term births of small for gestational age infants: a population-based study of risk factors among nulliparous women. BJOG: An International Journal of Obstetrics \& Gynaecology. 1998 Sep 1;105(9):1011-7.

27. Holick MF, Binkley NC, Bischoff-Ferrari HA, Gordon CM, Hanley DA, Heaney RP, Murad MH, Weaver $\mathrm{CM}$. Evaluation, treatment, and prevention of vitamin D deficiency: an Endocrine Society clinical practice guideline. The Journal of Clinical Endocrinology \& Metabolism. 2011 Jul 1;96(7):1911-30.

28. Loy SL, Lek N, Yap F, Soh SE, Padmapriya N, Tan KH, Biswas A, Yeo GS, Kwek K, Gluckman PD, Godfrey KM. Association of maternal vitamin D status with glucose tolerance and caesarean section in a multi-ethnic Asian cohort: the growing up in Singapore towards healthy outcomes study. PloS one. 2015 Nov 16;10(11):e0142239.

29. Mithal A, Kalra S. Vitamin D supplementation in pregnancy. Indian journal of endocrinology and metabolism. 2014 Sep;18(5):593. 